\title{
CULTURA NACIONAL-POPULAR \\ E CIRCULAÇÃO TRANSNACIONAL. \\ BRASIL E ANGOLA NO PROJETO KALUNGA
}

\author{
NATIONAL-POPULAR CULTURA \\ AND TRANSNATIONAL CIRCULATION. \\ BRAZIL AND ANGOLA IN THE KALUNGA PROJECT
}

\author{
Andréa Borges Leão* \\ Mariana Mont'Alverne Barreto Lima**
}

\section{Introdução}

Em 1980, momento de expansão da economia capitalista, uma caravana de artistas, produtores e técnicos brasileiros reunidos no Projeto Kalunga fazia a travessia do Atlântico com o objetivo de divulgar a música popular no exterior. A equipe partiu do Rio de Janeiro rumo à recentemente constituída República Popular de Angola, país africano que, no passado, estruturou nossa formação sociocultural. Foi realizada uma turnê político-artístico-musical pelas cidades angolanas de Luanda, Benguela e Lobito. Na bagagem, os músicos levavam uma sofisticada tecnologia aliada a uma diversidade em termos de gosto. Pode-se afirmar que, para os envolvidos no Kalunga, havia uma unidade de pensamento fundada na ideia da equivalência entre as culturas populares brasileira e angolana. Gostos, afınidades e o reconhecimento de matrizes comuns entre as músicas populares produzidas nos dois lados do Atlântico, igualmente estimularam o projeto da viagem.

0 objetivo deste ensaio é organizar uma discussão sobre a experiência de contato entre os dois campos nacionais de produção musical. Sob o enfoque do Projeto Kalunga, busca compreender o modo como

\footnotetext{
* Doutora em Sociologia pela Universidade de São Paulo - USP. Bolsista do CNPq. Professora na Universidade Federal do Ceará - UFC (Fortaleza/CE/BR). aborgesleao@gmail.com.

** Doutora em Sociologia pela Universidade Estadual de Campinas - Unicamp. Professora na Universidade Federal do Ceará - UFC (Fortaleza/CE/BR). mariana.barreto@pq.cnpq.br.
} 
se organiza um espaço transnacional de circulação entre culturas nacionais-populares. Com este propósito, o debate está dividido em dois tópicos. 0 primeiro lança um olhar retrospectivo sobre os caminhos das medições técnicas estrangeiras no longo processo de consolidação do mercado de bens simbólicos no Brasil. 0 segundo, se volta especificamente para a dinâmica dos dois campos nacionais da produção artística.

A estrutura de práticas e produções peculiares aos dois países encontrou a estrutura de seus campos musicais, possibilitando trocas econômicas e simbólicas capazes de transmutar as morfologias e fisiologias de um e outro, sem perder de vista as nuances diferenciadoras entre suas organizações industriais e domésticas, entre seus efeitos temporais e sagrados realizados num espaço de produção e consumo transnacional. Procuramos explicar de que modo a experiência do projeto Kalunga reposicionou os artistas brasileiros no cenário internacional como produtores e transmissores culturais, indicando que a heteronomia de um campo não invalida sua existência. Muito pelo contrário, os meios através dos quais ela se mostra constituem as forças e limitações que pesam sobre sua autonomia.

Sob o ângulo comparativo entre momentos da experiência histórica brasileira, podese argumentar que as trocas, transferências e empréstimos culturais efetivadas na circulação transnacional são relativas aos estágios e rumos da autonomização do campo da produção simbólica. Ou melhor, se os contatos protagonizados pela equipe do Projeto Kalunga, em plena consolidação de uma economia da cultura, não são os mesmo do que se entendia como influência no longo período de formação estudado por Fernand Braudel e Gilberto Freyre, o que efetivamente muda e torna-se relevante estudar é a dinâmica das mediações e redes de atuação sociopolíticas entre os agentes implicados em cada espaço nacional-popular.

\section{Cultura nacional-popular e circulação transnacional}

Na primavera de 1942, o historiador francês Fernand Braudel ${ }^{1}$ envia a Lucien Febvre, do cativeiro em que se encontrava na Alemanha, um ensaio analítico sobre o que até então formava o conjunto da obra publicada do sociólogo Gilberto Freyre. A amplitude temporal do olhar de Braudel sobre a dinâmica social brasileira numa das mais importantes interpretações sobre o passado do país constituía por si só um novo ângulo de abordagem. Mas, as grandes linhas traçadas pelo sociólogo, na visão do historiador, ao revelarem os processos de dominação com base no par relacional de senhores e escravos ia deixando pelo caminho outras figuras estruturantes na formação do Brasil. A paisagem composta inicialmente pela casa grande e a senzala, depois pelo sobrado e o mucambo, colocava no primeiro plano os indivíduos mais enraizados, estáveis, dependentes e adaptados ao mundo tropical, constituindo-se um ponto fixo de senhores, senhoras, padres e escravos. Outros personagens poderiam ser descortinados na aventura histórica brasileira, apontava o historiador. A massa humana de sedentários, rural ou urbana, privilegiada no modelo freyreano da civilização luso-tropical, continua Braudel, sempre esteve desafiada pela errância de uma massa humana de po-

1. Fernand Braudel veio integrado a um grupo de intelectuais franceses. Lecionou nos primeiros anos de fundação da Universidade de São Paulo, entre 1935 e 1937. 
bres e vagabundos, viajantes e aventureiros - os mascates e ambulantes, pequenos comerciantes estrangeiros - e por todas as variações de nômades - os ciganos, tropeiros, sertanejos, garimpeiros, seringueiros e bandeirantes - que circulavam pela Bahia, Pernambuco, Rio de Janeiro, Minas, Amazonas e São Paulo. Figuras muitas vezes sem-cidade e sem-casa (BRAUDEL, 2001, p. 69) desafiavam a lógica da família patriarcal pensada a partir do interior da casa grande, tornando o universo colonial brasileiro mais diversificado e complicado aos que se lançavam na sua interpretação.

Braudel certamente tinha em vista que no momento em que Freyre publicava os livros Casa grande e senzala (1933) e Sobrados e Mucambos (1936) a sociedade brasileira encontrava-se em pleno processo de modernização capitalista. 0 espaço de discussão que organiza no ensaio $\dot{A}$ propos de l'ouvre de Gilberto Freyre tem o propósito de revelar um jogo social estruturado na interdependência entre o sedentarismo e a errância. Interdependência entre duas visões de mundo, duas culturas e duas economias, uma agrária e outra mais instável baseada na troca de bens, no comércio internacional de mercadorias e na circulação de pessoas e ideias. Isso significa que tradição e modernidade acabaram por se encontrar e a estruturar um traçado de fundação social. Braudel nos mostra que estabelecidos e nômades sempre remeteram um ao outro. Foi esse par que ofereceu formas de expressão e impôs normas que deram lugar aos primeiros indícios classificatórios e divisões hierárquicas na produção dos bens simbólicos: nacional $\mathrm{x}$ estrangeiro, popular $\mathrm{x}$ erudito, original $\mathrm{x}$ cópia, dependência $\mathrm{x}$ autonomia, atraso $\mathrm{x}$ simultaneidade na recepção das ideias.

A crítica de Fernand Braudel a Gilberto Freyre, elaborada no início dos anos 1940, oferece uma orientação de leitura da obra porvir do sociólogo. Como todos os problemas e questões tem um passado, para ficar com o historiador Daniel Roche (2011), os da circulação da cultura, incluindo as versões do nacional e do popular, tão em vogas na atualidade, estiveram presentes nos trabalhos após Sobrados e mucambos. A partir de finais da década de 1940, Gilberto Freyre confere um lugar aos personagens errantes e mediadores entre culturas. Três obras se destacam : Ingleses no Brasil. Aspectos da influência britânica sobre a vida, a paisagem e a cultura do Brasil, Um engenheiro francês no Brasil e Nós e a Europa germânica. Em torno de alguns aspectos das relações do Brasil com a cultura germânica no decorrer do século XIX. Nelas, Freyre abre um caminho para o estudo dos contatos, observa apropriadamente Maria Lúcia Pallares-Burke (2001). Ao sugerir que o sedentarismo colonial conduziria às figuras da mobilidade pela interpenetração de culturas (1948, p. 35) e que, na maior parte das vezes, os estrangeiros situavam-se na base da exclusão colonial, Freyre vai ainda mais longe preconizando um método de leitura da formação brasileira. Ingleses, alemães e franceses vistos por ele como marias-borralheiras de nossa história (1948, p. 39) por não terem vindo ao país em viagens ofıciais e, com isso, não merecerem a devida atenção, exerciam a função de mediadores da circulação ao trazerem nas suas bagagens conhecimentos técnicos e racionais, experiências no comércio, na difusão de livros e periódicos, espetáculos de música e teatro, além do gosto por artigos oriundos de um consumo popular urbano e massificado na Europa.

Segundo Gilberto Freyre (2003), a vinda da corte portuguesa para o Rio de Janeiro, a abertura dos portos às nações ami- 
gas, em 1808, e o incremento do comércio de importação por navios estrangeiros desencadearam um movimento de reeuropeização de nossos modos de vida e pensamento. Observava-se a expressão de um sentimento de superioridade a tudo o que fosse herança dos tempos coloniais. Essa progressiva ocidentalização enfrentava os costumes já tradicionais de uma primeira europeização implantada pelos colonizadores ibéricos na consolidação da sociedade patriarcal. 0 primado ibérico aclimatou nos trópicos uma cultura oriental sob a influência do mouro, do judeu, dos árabes e negros africanos. Com isso, a nacionalização da cultura brasileira só podia resultar da assimilação das contribuições portuguesa, africana e indígena.

Por outro ângulo, durante a reeuropeização, as influências estrangeiras, através ou independentes de Portugal, também podem ser vistas como uma modalidade de diálogo entre culturas. A influência europeia se constituiria em uma forma da experiência de recepção, não podendo mais ser reduzida a uma pura e simples dominação colonial de mão única. Os contatos transculturais traziam um problema suplementar no caso do Brasil oitocentista insuficientemente desenvolvido, com altos índices de analfabetismo e ainda em vias de organização de um espaço nacional de produção simbólica. Se o processo de africanização foi interpretado na obra maior do sociólogo, os estrangeiros brancos e pobres ganham proeminência em obras menores e como intermediários necessários no processo de modernização do país.

Personagens obscuros, aventureiros, engenheiros e missionários que se movimentavam pelas zonas de comércio, arte e religião, nas primeiras indústrias e estradas de ferro, conformam uma cultura popular feita de contatos na vida de todo dia. Assim, as marias-borralheiras deixam as margens e suas redes de atuação se impõem no cenário de formação da cultura brasileira. Isso significa que o trabalho técnico - na época desqualificado e, portanto, ilegítimo - de indivíduos que dominavam o ferro e o aço, o vidro e o cobre, trazendo consigo as marcas de suas culturas de origem, ajudava a defınir a gênese de um mercado nacional-popular de bens simbólicos. E significa ainda mais a necessidade de problematização da concepção de estrangeiro e de europeu, como unicamente dominantes e imperialistas, que se costuma elaborar do passado.

No livro Ingleses no Brasil, Freyre, usando como fontes os anúncios de jornais e documentos consulares, dá vida aos transmissores culturais que trabalhavam nas companhias de mineração, nas fundições, em lojas de calçados e tecidos, ao lado de viajantes e cronistas da vida política célebres, como Maria Graham. Em relação aos franceses, os intercâmbios teriam sido protagonizados, primeiro, por piratas e contrabandistas de madeira, no período da colonização, depois pelos viajantes, cientistas, missionários, artesãos, marceneiros, padeiros, costureiras, alfaiates e, no século XIX, por profissionais especializados em certa influência igualmente de ordem técnica, junto ao contato com a fotografia, a pintura, a música, os livros, costumes e ideias (FREYRE, 1960). A respeito, Emilia Viotti da Costa (2000) chama a atenção para os choques entre as influências francesas e inglesas em disputa do controle econômico e da orientação espiritual de gerações de brasileiros. Freyre mostra que de personagens como o engenheiro Louis-Léger Vauthier, que residiu no Recife de 1840 a 1846 e realizou obras urbanas inovadoras, 
recebemos o gosto pelo trabalho manual. Isso significa que o processo de modernização da sociedade brasileira contou com as contribuições dos agentes da produção e da mediação técnica. Esses agentes estavam vinculados a uma lógica transnacional que ligava o Brasil às sociedades europeias. Estabelecidas as trocas, ainda que baseadas em desequilíbrios e assimetrias entre nações, o Brasil participava como espaço de recepção e mercado consumidor.

Emilia Viotti da Costa (2000, p. 284) cita como um marco na história dos contatos a instalação da Casa Garroux, em 1864, em São Paulo. 0 projeto intelectual e a rede de atuação de Anatole Garroux em diversos setores da incipiente produção cultural diversificava-se como importante centro difusor da cultura francesa. Sua livraria era ao mesmo tempo "tipografia, depósitos de vinhos, de guarda-chuvas, objetos de artes, etc". 0 mesmo se pode dizer da Livraria Garnier, fundada no Rio de Janeiro, em meados do século XIX. Comparando os percursos e a trajetória social de cada livreiro-editor ${ }^{2}$, tanto Anatole Garroux como Baptiste-Louis Garnier mantinham representantes e pontos de venda comerciais em outras províncias do Império, fazendo circular pelo interior do país artigos culturais diversos, brochuras baratas, gêneros populares como os romances folhetins, manuais escolares, livros importados diretamente das matrizes francesas, literatura traduzida e publicações de autores nacionais, tornando a dependência cultural em relação aos países europeus uma interdependência. Citando Freyre, Emília Viotti (2000, p. 285) resume o traçado da nossa modernização: "o papel desempenhado pelo que se costumou chamar de agentes técnicos foi considerável, muito maior do que é costume avaliar-se".

Assim, as convenções atribuídas ao popular na cultura brasileira foram pegas na lógica histórica da modernização e da circulação transnacional, ao mesmo tempo em que sofriam deslocamentos de sentido em momentos propícios ao debate interno sobre a identidade nacional. As formas de pensar a cultura nacional-popular, de acordo com Renato Ortiz (1994), têm uma historicidade e dependem, em boa medida, do olhar que os cientistas dirigem ao mundo social. É a relação entre cultura e política que remete ao debate sobre o popular e o nacional no Brasil (ORTIZ, 1994, p. 160), continua o sociólogo, que igualmente chama a atenção para duas grandes tradições intelectuais fundadoras de um pensamento sobre o nacional-popular. Uma, percebe a cultura popular do ponto de vista do folclore e é mais antiga, tendo sido inaugurada, no século XIX, por Silvio Romero e Celso Magalhães; a outra, o associa às classes subalternas e teve seu momento principal nos meados dos anos de 1950. Esta última vertente conhecerá vários matizes ideológicos e "será reformista para o ISEB, marxista para os Centros Populares de Cultura, católica de esquerda para o movimento de alfabetização e o Movimento de Cultura Popular no Nordeste” (ORTIZ, 1994, p. 162). Mas a cultura nacional-popular no Brasil também foi organizada com o advento do consumo de massa em decorrência da consolidação da indústria cultural. Com a disseminação das mercadorias simbólicas e

2. Sobre a expansão das livrarias francesas em São Paulo, de finais do século XIX e início do século XX, e sobre a Casa Garroux em particular, consultar: Deaecto, M. M. 0 império dos livros. Instituições e práticas de leitura na São Paulo oitocentista. São Paulo: Edsup, 2012. 
com a entrada do Estado como agente no mercado da cultura, a partir dos anos 1970, os gêneros da produção popular entram na lógica transnacional do consumo massivo. O significado do popular na indústria cultural acaba também reconfigurando a questão do nacional/estrangeiro, observa Renato Ortiz (1994, p. 190), na medida em que se abre um momento de maior autonomização da cultura brasileira.

Observamos que esta autonomia se traduzirá em diferentes meios, evidenciando forças e limitações que sempre estiveram presentes na constituição da produção da cultura popular no Brasil. Agentes e instituições envolvidos nestes processos, mesmo nos tempos fortes de suas nacionalização e internacionalização, se é que é possivel separá-las, não prescindiram das injunções externas e de seus critérios de diferenciação específicos, na busca por sua autonomização. Por isso, o ensaio de Braudel continua a alargar os horizontes dos estudos sobre as redes de atuação dos mediadores culturais. Ele objetiva a impossibilidade de se trabalhar com os fenômenos de nacionalização das culturas, encerrando-os sobre si mesmos. Já nos primeiros passos das marias-borralheiras na montagem do que viria a ser uma indústria da cultura no Brasil, no século XX, o país de consumidor passa a transmissor e, sobretudo, a produtor transnacional e protagonista do encontro entre culturas.
0 que acontecerá em 1980, reforça nossa hipótese. Em um momento de expansão da economia capitalista, uma caravana de artistas faz a travessia do Atlântico em sentido inverso à história das relações Brasil/ África, com o objetivo de divulgar a música popular no exterior, rumo à recentemente constituída República Popular de Angola, país africano que, no passado, estruturou nossa formação sociocultural ${ }^{3}$. A turnê político-artístico-musical pelas cidades angolanas de Luanda, Benguela e Lobito, empreendida pela equipe do Projeto Kalunga leva na bagagem uma sofisticada tecnologia musical aliada a uma diversidade em termos de gosto. Impensável para um país de economia periférica, identificado às condições de dependência, desigualdade, pobreza e subdesenvolvimento, como o Brasil. 0 fato é que, apesar disso, possuíamos um mercado de bens simbólicos consolidado nos termos de um campo da produção, circulação e consumo artístico, na década de 1980 , capaz de executar projeto semelhante.

\section{Projeto Kalunga: rede de atuação musi- cal brasileira e angolana}

No interior de um campo, produção e recepção se equivalem quando o objetivo é conhecer a sua conformação. Ou melhor, como se formam seus produtores, os agentes

\footnotetext{
3. De acordo com Meihy (2004, p. 126), “[...] Angola foi, entre as diversas regiões da África, a que maior número de escravos teria enviado ao Brasil. Porque do conjunto de negros em trânsito de uma parte à outra, que tangencia o total de quatro milhões e duzentos mil, calcula-se que cerca de três milhões tenham derivado de Angola. Apesar disso, em estudos atentos à influência angolana no Brasil esse montante é pouco contemplado e isso abisma as distâncias de entendimento cultural entre os dois pólos. Por outro ângulo, de forma especular (sic), também a influência brasileira em Angola é desprezada, deixando espaço à frustração de um setor que poderia servir de base compreensiva tanto para a cultura popular como à política dos dois países".
} 
sociais e suas lógicas, assim como as obras que se constituem em objetos de crenças e disputas nestes espaços. Se o propósito é explicar as singularidades dos criadores e de suas produções, invariavelmente estaremos objetivando e interpretando as relações sociais e de força que, em conjunto, movem esses espaços sociais escolhidos analiticamente. Assim é que artistas, obras e consumidores carregam em si o próprio campo da produção artística; cuja eficácia de funcionamento reside exatamente na interdependência entre eles. (BOURDIEU, 2007a).

Nesse ponto da discussão, reforçando o que já anunciamos, destacaremos como em dois campos nacionais da produção artística, brasileiro e angolano, a estrutura de suas práticas e produções encontrou a estrutura de seus campos musicais, possibilitando trocas econômicas e simbólicas capazes de transmutar as morfologias e fisiologias de um e outro, sem perder de vista as nuances diferenciadoras entre suas organizações industriais e domésticas, entre seus efeitos temporais e sagrados, realizados num espaço de produção e consumo transnacional.

Com um mercado de bens simbólicos consolidado, na década de 1980, no Brasil, produção, circulação e distribuição dos produtos culturais administradas pelo Estado se desenvolveram subordinadas a instituições públicas específıcas, que contribuíram para a estruturação de "um novo campo da cultura onde as formas de dominação tomam configurações distintas” (ORTIZ, 1994, p.78), em que as dimensões do consumo e da distribuição passaram a ser valorizadas como ponto central da ideologia do desenvolvimento cultural nacional.

Neste ambiente, a questão da cultura popular, colocada em termos de hegemonia, já não se vincula apenas à tradição popular regional - identificada pelo Cen- tro Popular de Cultura - CPC, por exemplo, como "arte do povo" - nem às conotações e posições políticas à esquerda que daí derivaram marcando, por exemplo, a produção da música popular brasileira até aquele momento. A cultura passou a organizar-se sob bases industriais, o espaço de dominação cultural articulou-se de outro modo, fazendo com que questões como o nacionalismo, tal como considerado nos anos 60 , perdessem sentido, visto que o Estado, ele mesmo, criou instituições (EMBRAFILME, FUNARTE, TV Globo) que efetivamente implementaram um real desenvolvimento da cultura brasileira, sem prescindir do apoio das empresas privadas para a consolidação do desenvolvimento industrial de um mercado cultural (ORTIZ, 1994a, 1994b; MICELI, 1994; RIDENTI, 2000).

De acordo com Ortiz (1994b), uma despolitização da cultura, advinda na esteira da consubstanciação do nacional na existência das agências governamentais, fez com que os bens que expressassem uma cultura popular tivessem seus conteúdos modulados para atender um público amplo, retirando-se deles particularidades que impedissem sua ampla aceitação e consumo.

No contexto de valorização das dimensões do consumo e da distribuição como pontos centrais da nova hegemonia no desenvolvimento cultural do país, os novos agentes - o Estado e as companhias privadas - empreenderam políticas públicas de difusão da produção de bens culturais importantes. A circulação destes produtos realizava-se de diferentes maneiras, contando com a distribuição nacional dos bens em seus suportes físicos, cujas propagandas contavam com o incremento de um sistema de telecomunicações integrado nacionalmente que, com ajuda das redes de rádio e televisão, e com a consolidação de um 
mercado dos impressos, contribuíam para a venda em todo o país daquilo que os centros econômicos concebiam. Este sistema constituído de divulgação e distribuição arrimava-se ainda no trabalho das instituições públicas criadas para organizar cada um dos campos da produção dos bens simbólicos, capazes de divulgar, por intermédio de políticas e projetos culturais específicos, a "cultura brasileira" em suas variegadas expressões quer fossem nos filmes de longa-metragem, nas telenovelas, na literatura, nas propagandas ou nas músicas.

No caso da música popular, as caravanas do Projeto Pixinguinha 1979, organizadas pela Fundação Nacional de Artes (FUNARTE), com apresentações musicais em diferentes capitais brasileiras, funcionaram como meio de divulgação e rendimentos financeiros importantes para muitos artistas populares e produtores de música. 0 Projeto Pixinguinha estreara em 1977 e resistiu, na sua primeira edição, até os anos de 1980, experimentando modelos que se modificaram com frequência. Como política pública para divulgação da música popular brasileira e formação de plateias para além das capitais Rio de Janeiro e São Paulo, inseriase numa clara política de integração regional, financiada pela FUNARTE, secretarias municipais de cultura e universidades que, porventura, fossem responsáveis por recepcionar os grupos em excursão. (TAVARES e LEMOS, s.d; ALMEIDA, 2009) ${ }^{4}$.

Nessa articulação entre Estado e indústrias culturais, nas próprias edições anuais do Pixinguinha, podemos observar que os artistas selecionados para os shows, assim como seus produtores e diretores, eram profissionais vinculados às grandes companhias de discos, por contratos de trabalho de longa ou curta duração. Boa parte destes mesmos artistas e produtores estará envolvida no Projeto Kalunga, como mostraremos adiante. ${ }^{5}$

Temos então uma nova hegemonia no terreno da cultura popular onde entram em disputa a "resistência" dos grupos de artistas e profıssionais especializados e as forças da “incorporação", animadas pelo Estado e pelas grandes companhias operando como grupos dominantes. Trocas e negociações entre estes agentes e seus mediadores vão marcar o desenvolvimento da cultura popular, agora brasileira e não mais nacional. Se por um lado a categoria popular passou a significar consumo massivo, por outro o "popular politizado", identificado à música popular urbana produzida ao longo dos anos de 1960 e 1970, uma vez consolidado, ampliou seu

4. Chamamos de primeira edição do Projeto Pixinguinha as versões que compreendem suas realizações no período entre 1977 e 1980. A partir dos anos 2000 temos novas edições, com novos objetivos e formatos. Ver ALMEIDA, G.S.B. Projeto Pixinguinha: 30 anos de música e estrada. Dissertação de Mestrado, CPDOC/FGV-RJ, 2009.

5. Ratificando nossa afirmação, para o ano de 1979, os diretores artísticos para os espetáculos eram: Antônio Chrysóstomo, Tárik de Souza, Roberto Moura, Arthur Laranjeira, Sérgio Cabral, Oswaldo Loureiro, Maurício Tapajós, Kleber Santos, Érico de Freitas, Milton Pina, Tereza Aragão, Vital Santos, Paulinho Lima, Lígia Ferreira, Fernando Faro e Túlio Feliciano. s/a. Jornal Última Hora, 03/04/1979 In TAVARES, B. e LEMOS, A. Brasil Memória das Artes. Apostila Digital № 3 - Projeto Pixinguinha 1979. Disponível em www.funarte.gov.br/brasilmemoriadasartes/acervos/\#pixinguinha. Acesso e impressão em 15/03/2014. Dentre eles, alguns, importantes mediadores e intelectuais na constituição e fomento daquilo que se estabeleceu como a mais legítima música popular brasileira. Para uma discussão mais acurada sobre isso ver Fernandes (2012). 
espaço de atuação, buscou suas origens populares para além das fronteiras nacionais. Seus intelectuais - compositores, intérpretes, produtores, jornalistas, críticos musicais e demais profissionais - procuraram eles mesmos elementos para a reconstrução de um momento inaugural de sua tradição popular, numa elaboração intelectual que marcasse sua distinção entre o internacional-popular massivo do período e o nacional-popular segmentado dos anos anteriores.

0 Projeto Kalunga foi emblemático neste sentido, e evidenciou com clareza as reconfigurações no interior daquilo que se definiu como música popular brasileira a partir daquele momento. Uma produção musical que amalgamou a música popular urbana e regional forjada em diferentes momentos históricos, na sincronia das lutas ideológicas específicas de constituição da cultura popular no Brasil. Por outras palavras, com um mercado consumidor de bens simbólicos consolidado, a segmentada música popular brasileira, gozando de prestígio e consagração afırmou sua autonomia, assegurou a legitimidade de seu valor social, frente à heteronomia da música popular massiva nacional e/ou estrangeira.

Em 1980, uma turnê político-artísticomusical pelas cidades angolanas de Luanda, Benguela e Lobito marcou a concretização de um convite que havia sido feito à Chico
Buarque de Holanda alguns anos antes. De acordo com o próprio artista, os angolanos

[...] conheciam o Brasil e nossa música de forma apaixonada. 0 primeiro contato comigo foi feito através do Ruy Guerra, que é moçambicano. 0 pessoal da embaixada de Angola pediu para que eu organizasse a viagem, o Projeto Kalunga. Me procuraram para ver se eu conseguia levar outros artistas. Eu não sei organizar nada, apelei para Fernando Faro. Um dos nomes que eles mais falavam era Caymmi, que era um mito, que eles veneravam. Eu convenci Dorival via Danilo: "Danilo, ajuda a gente”. Achei que era difícil e ele topou. E foi todo mundo de graça. (Chico Buarque apud CAYMMI, 2014, p. 467).

Coube à Secretaria de Estado da Cultura de Angola e à União Nacional do Trabalhadores Angolanos (UNTA) a promoção da viagem. A caravana composta por 64 pessoas, dentre elas músicos, compositores, intérpretes, instrumentistas, técnicos, produtores, jornalistas, cinegrafistas, viajou entre os dias 06 e 18 de maio de 1980. A recém constituída República Popular de Angola, sob o comando de Agostinho Neto, mesmo após o Movimento Popular de Libertação de Angola (MPLA) firmar-se no poder, enfrentava uma guerra civil que se estenderia por todo o Século XX. ${ }^{6}$

6. Se o Estado angolano se estruturava em meio a uma guerra civil sobre as bases de um regime revolucionário que procurava realizar as propostas que levaram o MPLA ao poder, o Estado brasileiro iniciava a passo curto sua abertura política, ao promulgar a Lei da Anistia em 1979. As negociações entre os dois regimes para a realização da viagem são pouco conhecidas, os documentos sobre o evento são raros, e as informações obtidas em matérias jornalísticas e entrevistas com parte dos integrantes da comitiva, sobre este ponto, são limitadas. Exceções são encontradas nos trabalhos de Castro $(2012 ; 2013 ; 2014)$. Sobre isto, por exemplo, ele mostra que mesmo tendo aceitado a soberania angolana nas primeiras horas de sua independência, o governo brasileiro não reconheceu oficialmente a viagem dos artistas brasileiros. No caso da imprensa brasileira, para dimensionarmos a escassez de informações, as reportagens sobre a turnê e sua repercussão nas cidades angolanas são pouco relevantes e muito sintéticas; exceto os artigos de Dul- 
Ao aceitar o convite que lhe havia sido feito, Chico Buarque sugeriu a Fernando Faro, a produção e montagem dos espetáculos musicais em Angola. (TUPY, 1980a, p.42; CASTRO, 2014, p.146, CAYMMI, 2014, p.467). Faro, além de consagrado produtor de inovadores trabalhos na televisão e na indústria fonográfica, havia dirigido, em 1979 e naquele ano de 1980, os shows do Primeiro de Maio no Riocentro, na cidade do Rio de Janeiro. Os shows do Primeiro de Maio além de homenagear os trabalhadores - e terem, nestas duas versões, suas rendas revertidas para o movimento dos operários grevistas de São Paulo (CASTRO, 2013. p. 561) -, marcaram as sequência dos "protestos políticos musicais" idealizados e executados por Fernando Faro. ${ }^{7}$ Segundo Dulce Tupy (1980a), jornalista que acompanhou a comitiva à Angola, Faro, ao ser incorporado ao Projeto,

contactou outros artistas e logo um esboço de show estava montado: haveria de ter uma parte nordestina, samba urbano e sambão. Dorival Caymmi foi um dos primeiros a aceitar o convite. Aos poucos, outros artis- tas aderiram ao Projeto. Afinal, a identificação entre Brasil e Angola encontra na cultura popular um forte referencial comum. Grande parte do vocabulário, da culinária, dos folguedos tradicionais, do misticismo e do carnaval refletem a influência e inter-relação dos povos africanos em terras brasileiras, sobretudo das populações de Moçambique e Angola. (p.42)

A crença no encontro entre as culturas populares “irmãs" representava fortemente uma unidade de pensamento entre os envolvidos pela viagem; assim como as descobertas entre gostos comuns e afınidades entre ambas, e a identificação de raízes musicais indivisas entre as músicas populares brasileira e angolana. Isso aparece com força quando, por exemplo, os participantes relembram as apresentações de João do Vale,

Angola foi em 1980, acho que umas 60 pessoas viajaram com Faro e Chico. Lembro bem do João, totalmente independente, ele suima, saia de noite e era proibido sair de noite porque era época da guerilha, então era perigoso, eles falavam. 0 João saia e voltava

ce Tupy (1980a) e Jakobskind (1981). 0 primeiro é, também, um dos mais completos relatos sobre a viagem, lá a jornalista elenca a mais completa lista dos integrantes do grande grupo de viajantes: Fernando Faro, Chico Buarque, Rui Guerra, Francis e Olívia Hime, Bahia, Edu Lobo, Wanda Sá, Miúcha, Cristina Buarque, Pií (Maria do Carmo Buarque de Holanda), Marieta Severo, Elba Ramalho, Djavan, Geraldo Azevedo, Dona Yvone Lara, Martinho da Vila, Clara Nunes, João Nogueira, Grupo Nosso Samba, Quinteto Violado, João do Vale, Dorival e Danilo Caymmi, Ruy Faria (MPB 4), Chico Batera, Paulinho Sawer, Café, Novelli, Wellington Lima (produtor), Lessa (organizador), Marcelo, Bolino, Zé Luís, Alexandre, Roberto, Angelo, Lelé e Caldeira (estes últimos compunham parte da equipe técnica), além de jornalistas (Dulce Tupy), fotógrafos (Yolanda Andreato), cinegrafistas (Tânia Quaresma, do Brasil, e uma equipe de televisão alemã), radialistas (Fernando Mansur) e demais técnicos de som, iluminação, etc. (TUPY, 1980a, p.43; CAYMMI, 2014, p.468; CASTR0, 2012, p.65).

7. Fernando Faro (1927-2016) produziu shows em oposição à ditadura militar, pela abertura política, organizou o comício pelas Diretas Já em São Paulo, além de ter criado os programas de televisão sobre música popular: Ensaio, Divino Maravilhoso, Móbile, Hora da Bossa e TV Vanguarda. Dicionário Cravo Albin da Música Popular Brasileira. Fernando Faro. Disponivel em http://dicionariompb.com.br/fernandofaro/dados-artisticos. Acesso em 27/09/2016. 
a hora que queria, ninguém pecebia que ele não era angolano, ele passava pela portaria e ninguém falava nada. No palco era aquela coisa linda, forte, de pés descalços, era emocionante. Era uma coisa de uma força de interpretação que impressionava brasileiros, como nós, e angolanos também. (BUARQUE, C., 2013, p.3).

Em Angola o Chico me chamou para ser o diretor musical e conheci de fato o João aí por volta de 79. Era uma caravana enorme e o João foi quem mais me impressionou. Ele foi o segundo ou terceiro a descer a escada do avião, e ele chegou e beijou o chão e foi impressionante. Ele comentava que seus avós tinham vindo de Angola. A gente se aproximou muito na viagem. Ele era um artista excepcional e foi reconhecido assim em Angola. A viagem foi muito organizada, tocamos em muitos lugares, para muita gente. Quando a gente voltou, aconteceram uns trabalhos, principalmente com a Miúcha [...]. No Projeto Pixinguinha, da FUNARTE... e o João estava dentro dessas coisas. A música dele era música para tudo, todos os lugares e plateias. Ele era um poeta, as pessoas percebiam a beleza de sua poesia. Um poeta que não sabia ler e escrever bem, e não precisava porque tinha uma força de se expressar, a beleza superava. (NOVELLI, 2013, P. 3).

Para Jakobskind (1981), em artigo publicado quase um ano após a realização do evento, a travessia empreendida sob a capitania de Chico Buarque e Fernando Faro representou,

Uma nova etapa se abre no relacionamento Brasil-África. Não estamos falando do relacionamento oficial, mas de um encontro entre povos, com raizes culturais que se cruzam. Essa manifestação, que não é nova, mas que se concretiza hoje de forma incontrolável, pode ser identificada com mais vigor na música. 0 que era um privilégio de alguns cantores e compositores, marcadamente influenciados e preocupados com a contribuição africana na nossa formação cultural, de repente se populariza, emociona e passa a ocupar um espaço maior na produção popular brasileira. (p.58)

\section{E continua,}

Há seis meses, um grupo de artistas brasileiros esteve em Angola divulgando a nossa música. Não era no estilo das viagens à Europa ou aos Estados Unidos, para cantar samba. Era uma experiência nova, rica. Como se todos tivessem a oportunidade de entrar numa máquina do tempo e voltar ao passado, se misturar com um dos fortes segmentos que influenciaram a nossa cultura musical. Principalmente num momento em que as manifestações culturais de um povo se dão livremente, sem a interferência do colonizador. E aí está a importância do acontecimento: é a nova realidade política nos jovens paises africanos que possibilita um relacionamento novo entre nossos povos. (Id. Ibidem)

Outra vez aparece a ideia de que as duas culturas apresentaram uma à outra suas músicas populares. No Brasil, a natureza e a política da cultura popular tinham, a partir da hegemonia do Estado autoritário e de uma indústria cultural consolidada, definido o que era sua música popular; subdividindo-a em diferentes gêneros musicais, conforme avançou em seus processos de produção, distribuição e consumo. 0 que signifıca dizer que, internamente, seus limites, a partir de agora, não se restringiam a um só gênero, estilo ou movimento musical, externamente, extrapolaram as frontei- 
ras nacionais, buscaram suas origens e tradição fora da nação. Lideranças artísticas, intelectuais e moralmente importantes no campo da música popular brasileira levaram a outro continente parte de seus mais notáveis recursos (compositores, intérpretes, instrumentistas, técnicos, repertórios, etc.), mas igualmente projetaram a estrutura alicerçada do mercado brasileiro de música. Isso talvez não pudesse ter acontecido em outra época, somente neste início de 1980, quando o estabelecimento de um mercado de bens simbólicos no país fez com que o nacional já não defınisse mais nem a cultura tradicional (e suas regionalidades) e nem a popular de mercado. (ORTIZ, 1994a; MICELI, 1994; RIDENTI, 2000).

Angola vivia uma situação adversa; os novos tipos de organização da cultura envidavam esforços para superação da hegemonia portuguesa, para o estabelecimento de uma ideologia da cultura nacional em oposição à tutela do antigo império e em convergência com os elementos constitutivos da cultura brasileira, também uma excolônia portuguesa, de sua música popular. A música folclórica, por exemplo, era considerada um anacronismo, em resistência à ela organizava-se a "música tradicional, não contaminada pelo colonialismo branco, e música das cidades [das diversas etnias e regiões do país] com influência do mundo ocidental”. (TUPY, 1980a, p. 45).

A música angolana foi apresentada, por seus poucos mediadores, como a "autêntica música tradicional popular”, pronta a mostrar seus pontos de inflexão, suas linhas de continuidade e ruptura com a música brasileira. A respeito das frágeis injunções dos mediadores, profissionais da cultura, indústrias culturais, artistas, etc, a declaração de Martinho da Vila, que estivera em Luanda em 1972, é reveladora não só do estágio inicial da produção de música gravada no país, mas é relevante pelo recurso comparativo que o artista aciona para refletir sobre essa condição, diz ele "lá não existe RCA, Polygram, Ariola, CBS, nada disso". ${ }^{8}$ (TUPY, 1980a, p. 43).

A inexistência das grandes companhias reforçava positivamente a lógica da produção artesanal da música tradicional angolana, atribuindo-lhe certa "autenticidade", liberdade de realização; dentro da lógica mercantil de produção da música popular brasileira, justamente em razão do estágio inicial do mercado angolano, a denúncia a um certo "oportunismo" do mercado em relação ao que a viagem poderia render em termos de realização de shows e discos, suscitou pequenos debates. Sobre a primeira questão as declarações se davam nos seguintes termos,

Durante a dominação portuguesa, a música popular brasileira chegava à África de uma forma dispersa, unilateral, sem um retorno, sem uma troca, pela repressão cultural exercida pelos colonizadores que não permitiam que a explosão rítmica africana se exprimisse e chegasse até nós da forma que chega agora. Há um interesse, um sentimento que nos une. A libertação de Angola e Moçambique não foi apenas uma libertação política, mas também cultural. (JAKOBSKIND, 1981, p. 58.).

8. Noutros termos, Tupy (1980a, p. 45) corrobora a mesma ideia ao escrever, "as condições da indústria fonográfica, praticamente paralisada desde a fuga dos técnicos portugueses, já não permite que o riquíssimo som do Ngola Ritmo se espalhe pelos musseks (favelas) como antigamente”. 
Os angolanos conhecem bem o Brasil desde muito tempo. Encontrei gente que guardava recortes de revistas brasileiras da década de 50. $\mathrm{O}$ Brasil era um ponto de referência. $\mathrm{Na}$ medida em que a cultura popular era reprimida pelos colonialistas, eles buscavam no Brasil as coisas que não podiam ser manifestadas lá, porque os opressores não deixavam. Hoje, os angolanos continuam olhando com interesse para o Brasil, mas a história mudou. Agora somos nós que vamos lá em busca das nossas origens. (Chico Buarque apud JAKOBSKIND, 1981, p.63).

A respeito da segunda questão, isto é, a crítica à hegemonia do mercado fonográfico na orientação do evento para a produção de produtos conexos, as justificativas e os contra-argumentos assumiram os seguintes tons,

Há quem interprete o posicionamento atual de Alcione $^{9}$ como oportunismo musical com interesses comerciais - a música angolana estaria sendo redescoberta e poderia trazer dividendos financeiros. Alcione responde aos que levantaram essa questão: "Oportunismo? Acho que não. Seria, se a música angolana tivesse estourado no mundo inteiro. Não é nada disso. Nós não ouvíamos música angolana. Fomos lá buscar. Isso não é oportunismo [...] (JAKOBSKIND, 1981, p.61).
Discordo dos que dizem que a música com raizes africanas é moda. Aqui no Brasil a ida de 64 músicos brasileiros não teve o destaque e a importância que deveria ter tido. A moda se impõe através de parâmetros burgueses. 0 que houve foi um contato direto entre dois povos através de caminhos próprio. (Chico Buarque apud Id. Ibidem, p. 63).

Sobre este embate poderíamos afirmar que, para os críticos, a travessia transatlântica era econômica em suas metas; e para os artistas e músicos era simbólica em seus meios e fins. (BOURDIEU, 2007a; BOURDIEU, 2007b). 0 certo é que tal clivagem, marcando as relações de força no campo dos produtores culturais, contribuía para fomentar a crença na importância daquilo que faziam os artistas, técnicos e os outros profissionais.

Para Chico Buarque, a viagem foi cultural e política; se diferentes produções daí se originaram, elas se deveram antes as trocas entre os dois países, as duas culturas. ${ }^{10} \mathrm{Em}$ seus argumentos os efeitos econômicos são racalcados, sobressaindo-se os princípios de igualdade. À época, a agência de notícias Angop - UPI publicou uma declaração sua que só confırma a nitidez dos objetivos da travessia para o artista, "Chico Buarque afirmou [...] que o grupo traz uma "mensagem de solidariedade e de luta" para todos

9. Não há ao certo como indicar se Alcione viajou à Angola em 1980 pelo Projeto Kalunga. Todavia, na longa matéria de Jakobskind (1981, p. 62) sobre o Projeto, há um depoimento da cantora com suas impressões sobre o país, visitado por ela, em turnê, naquele mesmo ano, alguns meses após a grande excursão. As controvérsias aparecem nos poucos materiais existentes. Paschoal (2000, p. 157), por exemplo, afirma que ela compôs o elenco do Kalunga. Tupy (1980a) não inclui seu nome na comitiva.

10. Identificam-se de modo direto à viagem à Angola as composições: Morena da Angola (Chico Buarque), Lá de Angola (João Nogueira), Luanda (Djavan), Nvula Ieza Kia - A chuva já chegou (Djavan e Felipe Mukenga), Velha Chica (Valdemar Bastos e Martinho da Vila), porém alguns discos e shows foram produzidos a partir do Projeto Kalunga. Para os artistas angolanos, além de suas apresentações para a comitiva brasileira em Angola, os músicos brasileiros interpretaram versões das canções de Ruy Mingas, Bonga, dentre outros. (CASTRO, 2013; s/a. Projeto Kalunga, a música brasileira em Angola. Caderno Cultura. Jornal O Globo, 14/05/1980, p.33). 
os angolanos cujas experiências revolucionárias todos os artistas presentes se sentem "muito satisfeitos" por poder apreciar". (ANGOP-UPI, 1980, p. 35).

0 compositor e intérprete havia estado em Cuba no ano anterior com um grupo restrito de quinze artistas. A passagem pela Ilha tinha propósitos semelhantes, e outra vez ele declarou a importância simbólica da aproximação entre as duas culturas,

Acho que o Brasil tem muito o que aprender com Cuba. 0 intercâmbio para nós é altamente lucrativo em todos os sentidos. E acho que culturalmente a gente já pode até atuar, já pode incrementar essa relação. [...] [Chico] explicava como a música brasileira acabou se incluindo na geografia cultural do Caribe: "Foi mais uma trama do García Márquez que sustenta e quer provar que o Brasil faz parte do Caribe [...]". (CALDAS, 1979, p.20).

Todos os brasileiros incluídos nos dois projetos estavam vinculados, por contratos de trabalho, ou outros tipos de relação, às grandes companhias produtoras de discos, ainda que não fossem elas as promotoras dos eventos. Ou seja, a motivação política da viagem não pode perder de vista o fato de que os artistas e profissionais envolvidos tinham carreiras consagradas. Temos então, um grupo de profissionais que busca modos e estratégias de internacionalização da música popular brasileira, de transnacionalização do campo da música popular, a partir de uma motivação que não é comercial, mas que pressupõe, no país, a consolidação de um mercado de bens simbólicos e de um campo da produção fonográfica (ainda que pouco autônomo e subalterno, porque sob a hegemonia das majors).

0 curioso neste trânsito é que no outro polo, o agente da troca tem uma produção restrita, com poder de circulação limitado, já que não existia um campo de produção cultural constituído, cujo monopólio de formação ainda era pretendido pelo Estado. Os dois espaços nacionais de produção musical, ainda que situados em posições muito distantes e desiguais, encontraram um no outro elementos de realização a partir das transposições operadas. Noutras palavras, como mostra Sapiro (2013, p.71), a existência de elementos semelhantes em culturas distintas é produto da circulação de modelos e trocas, confirmando a dimensão transnacional de todo campo. ${ }^{11}$

A isso acrescentemos o fato de que, mesmo as duas culturas populares subalternas estando em condições diferentes e desiguais, como mencionado, nenhuma é dominante. A dimensão transnacional de seus processos de circulação aponta para a existência de um campo de produção simbólica pouco autônomo e outro quase inexistente. 0 que pode parecer um paradoxo, é capaz igualmente de ser visto como uma excepcionalidade ilustrativa da tese de Sapiro (2013). Sobre isso, ela escreve,

[...] a construção das identidades nacionais é ela mesma operada em um processo transnacional de circulação do modelo de um país a outro [...]. [...] as lógicas de expansão dos mercados, as ambições hegemônicas e o colonialismo são três fatores de formação dos espaços de circulação e trocas ultrapassando os territórios nacionais. (SAPIRO, 2013, p. 74). 
Para a autora, a transnacionalidade de um campo presume sua existência nacionalmente. Brasil e Angola, mesmo sem campos de produção musical autônomos e constituídos ou consolidados, tocaram um campo transnacional, não se fecharam em seus espaços nacionais na realização dos fenômenos de circulação, trocas e transferências de suas músicas populares. É certo que por razões políticas afıns, mas culturalmente distintas, em razão do estágio de desenvolvimento de seus mercados de bens culturais. 0 Projeto Kalunga foi um evento onde os brasileiros justificaram sua participação sob os argumentos do apoio político a um país em ruptura e da busca por correlações entre as músicas populares brasileira e angolana; um acontecimento em que angolanos recepcionaram seus convidados como simpatizantes políticos do novo regime e como artistas iguais, "companheiros”, inclinados de boa mente a contribuírem para a construção de seu, ainda disforme, mercado nacional de música popular. 0 recém-formado Estado nacional angolano tenderia a fomentar a criação de um mercado de bens culturais no país, a identidade nacional que se constituía poderia ser, em alguma medida, devedora da cultura brasileira. Do mesmo modo a música brasileira realizara, na África, uma etapa importante de seu processo de autonomização e internacionalização. ${ }^{12}$

Por fım, é importante destacar que o campo da cultura é um lugar de política. (ORTIZ, 2001, p.195). O Projeto Kalunga acontece em 1980, quando a emergência de uma indústria cultural e de um mercado de bens simbólicos nacional redefiniu os significados do popular, afirmando uma cultura popular de mercado, alterando o discurso do nacionalismo e defendendo as políticas de massificação e internacionalização para a produção, distribuição e consumo dos bens culturais. A conotação claramente política da cultura popular observada nos anos de 1960, confundia-se com as hierarquias de "popularidade" entre os diversos produtos ofertados no mercado. Tínhamos uma indústria cultural inserida na atividade econômica e no sistema de instituições políticas, com um impacto sobre a população que longe de se realizar apenas como entretenimento e lazer, exercia funções paradidáticas e supletivas junto aos setores de baixa qualificação escolar. (MICELI, 1994, p. 59).

Aos poucos a cultura popular de mercado absorveu todos os produtos, classificando e hierarquizando sua popularidade, ainda que simbolicamente preservasse as marcas de distinção de parte deles, como no caso da música popular, aquela parcela da produção cujo prestígio havia sido construído pelo caráter político das obras. Os artistas, técnicos e demais profissionais da indústria cultural brasileira que foram à Angola, senão todos, boa parte deles estava comprometida com a ética e a estética de esquerda, tinha ciência de que suas habilidades artesanal e ideológica ainda atendiam aos anseios, às expectativas axiológicas e

12. Noutros termos, Castro (2012) ao examinar a história recente de Angola, para marcar as influências do Projeto Kalunga, escreveu “[...] tanto o samba como o semba [ritmo que tornou-se representativo da música popular angolana] podem ser pensados como culturas transnacionais - formados pelo movimento constante de viajantes e retornados que se mantém através do Antlântico - representantes das chamadas "nações diaspóricas", ao mesmo tempo em que se tornaram ritmos representativos das "nações territoriais" que se formaram no Brasil e em Angola”. (p.86). 
aos padrões estéticos de gosto dos públicos consumidores, mesmo quando disputavam com a produção massiva da cultura popular de mercado. Aliás, aí também, neste elemento, reside um ponto forte de construção de sua distinção em relação ao que se produzia em termos de música popular, consolidando a crença na sua qualidade, em seu elevado valor artístico, poético e musical, em contraposição à música popular de atributos inferiores, de gosto pouco distinto, anódina em termos poéticos, harmônicos e rítmicos, mas consagrada pelos números de venda, pelo mercado, pela massa da população consumidora.

A formação da música popular brasileira não pode ser pensada sem considerarmos os aspectos políticos e econômicos que a conformam, incluindo as relações de interdependência que mantém com outras tradições nacionais. Sua economia, como mostrada aqui, não se adequa às discussões em termos estritamente mercantis. Ela têm características diversas, lógicas de funcionamento e práticas multiformes que, por vezes, rechaçam, mascaram ou recalcam as "verdades objetivas" do próprio negócio, dos argumentos com base na racionalidade e no cálculo que orientam sua realização.

Procuramos matizar esta "dupla verdade” investida nas trocas simbólicas, em territórios nacionais distintos. Aquela que, como no caso da música popular brasileira, construiu seus padrões de distinção por caminhos divergentes aos do business musical, mas que o completam, porque são práticas de ação e lógicas de pensamento que precisam se combinar a formas de ser e fazer gerenciais, imprescindíveis para o desenvolvimento do negócio do ponto de vista artístico e comercial. ${ }^{13}$

Com o Projeto Kalunga essa música popular expressou sua autonomia e vigor no campo da produção musical brasileira; o ato político-cultural do grupo, por um lado, apoiou um regime de governo revolucionário, internacionalizou a música popular brasileira, transpôs suas fronteiras nacionais, inaugurando novos mercados e, por outro, reforçou os valores constitutivos de sua grandeza, incrementou a firmeza de seu domínio nas hierarquias dispostas no campo fonográfico dentro e fora do país. Enfım, a experiência do Projeto Kalunga reposiciona os artistas brasileiros no cenário internacional como produtores e transmissores culturais.

\section{Referências}

ANGOP-UPI. Angola conhece música brasileira. Caderno Ilustrada. Jornal FSP, 14/05/1980, p. 35.

ALMEIDA, G.S.B. Projeto Pixinguinha: 30 anos de música e estrada. Dissertação de Mestrado, CPDOC/FGV-RJ, 2009.

BARRETO, M. A trajetória de João do Vale e os lugares de sua produção musical no mercado fonográfico brasileiro. Revista ArtCultura, vol. 14, n.24, jan-jun,p.47-60, 2012.

João do Vale e a formação de um artista popular no Brasil, nos anos de 1950. Revista de Ciências Sociais, vol. 46, n.2, p.201-224, Jull - Dez/2015. 
0 artista popular e o contrato: lógicas divergentes na produção musical. Revista Ciências Sociais Unisinos, No 52, Vol. 2, Maio-Agosto/2016. P. 253-262.

BOURDIEU, P. Estrutura e gênese do campo religioso. In: MICELI, S. (Org.) Pierre Bourdieu - A Economia das Trocas Simbólicas. (Trad. Sérgio Miceli). 6a Edição. São Paulo: Perspectiva, 2007a.

BOURDIEU, P. A economia dos bens simbólicos. In: BOURDIEU, P. Razões Práticas - Sobre a teoria da ação. (Trad. Mariza Corrêa). 8aEdição. Campinas: Papirus, 2007b.

BRAUDEL, F. À propos de l'oeuvre de Gilberto Freyre. In: L'histoire au Quotidien. Paris: Éditions de Fallois, 2001.

BURKE. M. L. P. Ingleses no Brasil. Um estudo de encontros culturais. Tempo Social. Revista de Sociologia USP, vol.2,n.13,p.227-230, Novembro de 2011.

CALDAS, D. T. Brasileiros com Fidel: "tem uma aura”. Jornal Movimento, 13 a 19/08/1979. P.20.

CASTRO, M. B. de. Memória do Projeto Kalunga: música popular e construção de identidades entre Rio de Janeiro e Luanda (1975- 1980). In: Ferretti, S. (Org.). Museus Afrodigitais e política patrimonial. São Luís: EDUFMA, 2012. pp. 63- 92.

Memória e esquecimento do Projeto Kalunga: narrativas identitárias e cartografias musicais. 5th European Conference On African Studies. Lisbon University Institute. 27 a 29 de Junho de 2013. P.555 - 575. Disponivel em https:// repositorio.iscte-iul.pt/handle/10071/7595. Acesso em 18/08/2016.

"Memória do Projeto Kalunga" no Museu Afrodigital do Rio de Janeiro: Reflexões sobre identidades negras e africanas no Brasil (19751980). Revista Diversitas, Ano 2, n.2, p.126-150, Março - Setembro de 2014.

CAYMMI, S. Dorival Caymmi - 0 mar e o tempo. 2a Edição. São Paulo: Editora 34, 2014.

Dicionário Cravo Albin da Música Popular Brasileira Fernando Faro. Disponível em http://dicio- nariompb.com.br/fernando-faro/dados-artisticos. Acesso em 27/09/2016.

COSTA. E. V. Alguns aspectos da influência francesa em São Paulo da segunda metade do século XIX. Revista de História, n. 142-143,p.277-308, 2000.

DEAECTO, M. M. 0 império dos livros. Instituições e práticas de leitura na São Paulo oitocentista. São Paulo: Edsup, 2012.

FERNANDES, D. C. Os Maestros do Verbo: a constituição da legalidade interna da música popular urbana brasileira. Revista Sociologias, Ano 14, n. 31, p. 270-299,Set-Dez - 2012.

FREYRE, G. Sobrados e Mucambos. Decadência do patriarcado rural e desenvolvimento do urbano. São Paulo: Global, 2003.

Um engenheiro francês no Brasil. Prefácio do Professor Paul Arbousse-Bastide. 1. Tomo. Rio de Janeiro: José Olympio Editora, 1960.

Ingleses no Brasil. Aspectos da influência britânica sobre a vida, a paisagem e a cultura no Brasil. Rio de Janeiro: José Olympio Editora, 1948.

JAKOBSKIND, M. A. De volta às origens. Cadernos do Terceiro Mundo. Ano III, n.33. Rio de Janeiro: Ed. Terceiro Mundo, 1981.

MEIHY, J. C. S. B. 0 samba é Morena de Angola: oralidade e música. História Oral - Revista da Associação Brasileira de História Oral, n.7, p. 123141, junho de 2004.

MICELI, S. 0 papel político dos meios de comunicação de massa. In: SOSNOWSKI, S. e SCHWARTZ, J. (Orgs). Brasil: O Trânsito da Memória. São Paulo: EDUSP, 1994.

ORTIZ, R. A Moderna Tradição Brasileira. 5a Edição. São Paulo: Brasiliense, 1994a.

Cultura Brasileira e Identidade Nacional. 4ª Edição. São Paulo: Brasiliense, 1994b.

Sociedade e Cultura. In: SACHS, I; WILLHEIM, J. e PINHEIRO, P.S. (Orgs.). Brasil: um século de transformações. São Paulo: Companhia das Letras, 2001, p. 185 - 209. 
PASCHOAL, M. Pisa na Fulô mas não Maltrata o Carcará - Vida e obra do compositor João do Vale, o poeta do povo. Rio de Janeiro: Lumiar Editora, 2000.

RIDENTI, M. Em Busca do Povo Brasileiro: Artistas da Revolução, do CPC à Era da TV. Rio de Janeiro: Record, 2000.

ROCHE, D. Les circulations dans l'Europe moderne. XVII et XVIII siècle. Paris: Pluriel, 2011.

SAPIRO, G. Le champ est-il national? La théorie de la différenciation social au prisme de l'histoire globale In Actes de la Recherche en Sciences Sociales, Théorie du Champ, n.200, Décembre 2013. P.71 a 85.

s/a. Projeto Kalunga, a música brasileira em Angola. Caderno Cultura. Jornal 0 Globo, 14/05/1980, p.33

TAVARES, B.; LEMOS, A. Brasil Memória das Artes. Apostila Digital № 3 - Projeto Pixinguinha 1979. Disponivel em www.funarte.gov.br/brasilmemoriadasartes/acervos/\#pixinguinha. Acesso e impresso em 15/03/2014.

TUPY, D. Foi bonita a festa, pá... . Revista Módulo, n.59, p.42-45, Julho de 1980a.

TUPY, D. Entrevista com Chico Buarque. Jornal Movimento. 14 a 20/07/1980a, p. 19.

\section{Entrevistas}

BARRETO, M. Entrevista com Cristina Buarque, Paquetá-Rj, Dezembro de 2013. . Entrevista com Novelli, Rio de Janeiro-RJ, Outubro de 2013. 
RESUMO

Este artigo organiza uma discussão sobre a experiência de contato entre dois campos nacionais de produção musical, o brasileiro e o angolano. Sob o enfoque do Projeto Kalunga, que desloca uma caravana de músicos e produtores para o país africano, em 1980, o artigo estuda o modo como se organiza um espaço transnacional de circulação entre culturas nacionais-populares. Com este propósito, lança um olhar retrospectivo sobre os caminhos das medições técnicas estrangeiras no longo processo de consolidação do mercado de bens simbólicos. Uma das conclusões é a de que a experiência do Projeto Kalunga reposiciona os artistas brasileiros no cenário internacional como produtores e transmissores culturais.

\section{PALAVRAS-CHAVE}

Circulação transnacional. Cultura nacional -popular. Projeto Kalunga. Música popular brasileira. Mercado dos bens simbólicos.

\section{ABSTRACT}

The present paper traces a discussion on the contacting experience between two national fields of musical production: the brazilian and the angolan field. Under the light of the Kalunga Project that takes a caravan of musicians and producers to the african country in 1980, the article studies how a transnational space of Nationalpopular cultural trading takes form. With that in mind, the paper casts a retrospective view over the technical mediations during the long process that takes course in consolidating a market of symbolic assets. One of the conclusions we come to is that the experience of the Kalunga Project resettles the brazilian artists in the international scenario as producers and culture diffusers.

\section{KEYWORDS}

Transnational circulation. Popular-national culture. Kalunga Project. Brazilian popular music. Symbolic assets market. 
